\title{
Urinary Retention in Adults Male Patients: Causes and Complications among Patients Managed in a Teaching Hospital in North Western Nigeria
}

\author{
Muzzammil Abdullahi, Bashir Yunusa, Sharfuddeen Abbas Mashi, Sani Ali Aji*, \\ Sani Usman Alhassan \\ Urology Unit, Department of Surgery, Bayero University/Aminu Kano Teaching Hospital, Kano, Nigeria \\ Email: *saniaji2004@yahoo.com
}

Received 18 May 2016; accepted 10 July 2016; published 13 July 2016

Copyright (C) 2016 by authors and Scientific Research Publishing Inc.

This work is licensed under the Creative Commons Attribution International License (CC BY). http://creativecommons.org/licenses/by/4.0/

c) (i) Open Access

\section{Abstract}

Background: Urinary retention is one of the common urologic emergencies constituting a significant workload of urologists and non-urologists alike. Aims and Objectives: This study was undertaken to identify the causes and complications associated with urinary retention in adult male patients at AKTH, Kano. Patients and Methods: It was a prospective hospital-based study of 110 consecutive adult male patients who presented to Aminu Kano Teaching Hospital, Kano with urinary retention over 12 months. On presentation, a brief history was taken and rapid physical examination done; the urinary retention was relieved by urethral catheterization or suprapubic cystostomy. A detailed history and thorough physical examination findings were later obtained. Results: One hundred and ten patients were seen during the study period. There ages ranged from 17 to100 years with a mean of $56 \pm 19.3$ SD years. Patients within the age range $55-74$ years accounted for the largest group, $(25.5 \%+23.6 \%=49.1 \%)$. The most common cause of urinary retention in this study was benign prostatic hyperplasia (51.8\% of the patients). This was followed by urethral stricture $(20 \%)$, cancer of the prostate $(7.3 \%)$, urethral injury $(7.3 \%)$ and bladder tumour (6.4\%). More than half of the patients $(53.4 \%)$ presented with acute urinary retention, $30.5 \%$ presented with chronic urinary retention, and $16.1 \%$ were diagnosed to have acute-onchronic urinary retention. The complications of urinary retention found were: urinary tract infection (in $24.5 \%$ of patients), renal impairment (14.5\%), and anaemia (11.8\%). Conclusion: Urinary retention is commoner among the middle aged and the elderly. Benign prostatic hyperplasia remains the leading cause of urinary retention. Acute urinary retention was the commonest type of urinary retention; however, complications due to the retention were associated with chronic and acute-on-chronic urinary retention.

\footnotetext{
Corresponding author.
}

How to cite this paper: Abdullahi, M., Yunusa, B., Mashi, S.A., Aji, S.A. and Alhassan, S.U. (2016) Urinary Retention in Adults Male Patients: Causes and Complications among Patients Managed in a Teaching Hospital in North Western Nigeria. Open Journal of Urology, 6, 114-121. http://dx.doi.org/10.4236/oju.2016.67020 


\section{Keywords}

\section{Urinary Retention, Causes, Complications, Adult Male}

\section{Introduction}

Urinary retention (UR) is defined as inability to empty the bladder despite being distended with urine [1]. It may be acute or chronic. In the acute form there is a sudden inability to pass urine despite an urge to micturate. This is usually associated with suprapubic pain. Chronic urinary retention (CUR) is an inability to empty the bladder completely during voiding which usually is not associated with suprapubic pain [1]. There may sometimes be an acute urinary retention (AUR) on a background of chronic urinary retention (acute-on-chronic urinary retention) [2].

Urinary retention is one of the common urologic emergencies worldwide [2] [3]. It is a common complication of urologic diseases affecting the bladder and the urethra such as BPH, urethral stricture, cancer of the prostate and bladder/urethral stone [2].

The incidence is estimated to be 4.5 - 6.8 per 1000 men (aged 43 - 80 years) per year and this increases with increasing age [4] in the USA. Similarly, Hospital-based studies across West African Sub region have shown UR to be the commonest urologic emergency [5]-[7].

There are several causes of UR. These can be due to the following mechanisms:

1) Greater resistance to the flow of urine, either related to mechanical obstruction (e.g. urethral stricture, clot retention) or dynamic obstruction (e.g. increased $\alpha$-adrenergic activity in the smooth muscles of the prostate and the bladder neck in BPH) [4], 2) bladder over-distension (e.g. immobility, postponing micturition and 3) neurogenic causes (e.g. diabetic cystopathy) [8].

Urinary retention is associated with complications which are predominantly seen in CUR and acute-on-chronic UR due to gradual urine accumulation with subsequent stasis and increase in intravesical pressure.

Stagnation of urine leads to infection, which may involve the entire urinary system [9]. Often the invading organisms are urea-splitting, which causes the urine to become alkaline. This could give rise to septicaemia [9]. The bacterial spectrum in urosepsis may consist of 50\% Escherichia coli (E. coli), 15\% Proteus spp., 15\% Enterobacter and Klebsiella spp., 5\% Pseudomonas aeruginosa and 15\% Gram-positive organisms, according to different surveillance studies [10]. Candida spp. and Pseudomonas spp. occur as causative agents in urosepsis mainly if the host's defence is impaired [10]. Viruses are not common causes of urosepsis [10]. For patients with community acquired primary urosepsis, $E$. coli and other enterobacteriaceae are expected to be the predominant pathogens [10]. Calcium salts precipitate and form bladder or kidney stones more easily in alkaline urine. If both kidneys are affected, the result may be renal insufficiency. Secondary infection increases renal damage. Pyonephrosis is the end stage of a severely infected and obstructed kidney. The kidney is functionless and filled with pus [11].

Studies have shown that around half the men with CUR have increased serum creatinine or upper urinary tract dilatation. It seems generally accepted that this is more common in high pressure chronic urinary retention [12].

\section{Patients and Method}

It was a hospital based prospective study of 110 consecutive adult male patients who presented in urinary retention over one year (Jan-Dec, 2012). The patients were recruited through the emergency and the urology outpatient units of AKTH, Kano. Informed consent was obtained from each of the patients or their care-givers for recruitment into the study. Ethical approval was also obtained from the research ethics committee of the hospital.

On presentation, a brief history was taken and rapid physical examination done to establish if patient was in urinary retention and if it was acute, chronic or acute-on-chronic. The clinical assessment was done also to detect conditions that may require resuscitation such as dehydration, anaemia, UTI and renal impairment. UR was relieved as part of the resuscitation. Urethral catheterization was initially used to relieve the retention in most patients, where it failed or was contraindicated then SPC was done. Volume of urine drained was recorded. In AUR the urine was drained at once while in CUR it was drained gradually over the following 24 to 48 hrs. All catheterizations were done in an aseptic setting by doctors in surgery department. 
A detailed history including preceding LUTS and the duration, associated symptoms such as haematuria and passage of necrotic materials, history of precipitating factors (including trauma to the urogenital region, UTI, drugs etc), predisposing factors (e.g. past history of urethritis or urethral instrumentation, past history of passage of stone in the urine, past history of untreated childhood terminal haematuria, previous surgery for difficulty/ inability to pass urine etc.) were obtained and recorded. Other aspects of the history including history of trauma to the back or low back pain, low back swellings, diabetes mellitus, previous UR, and features of complications of UR (such as uraemic symptoms, fever, pain on micturition etc.) were all obtained.

Detailed physical examination findings including general appearance of the patient, presence or absence of pallor, dehydration, uraemic frosts, facial and pedal oedema were recorded. Vital signs were also recorded. Abdominal examination findings such as suprapubic swelling or tenderness, loin swellings or tenderness, inguinal and scrotal swellings, blood at the tip of penis/external urethral meatus, periurethral indurations, perineal sinuses and findings on digital rectal examinations (including enlarged prostate and whether it has benign or malignant features, presence of high riding prostate, presence of bladder tumour) were all looked for and entered into a questionnaire. Neurologic system examination including examination of the spine (for swellings, deformity, areas of tenderness) and limbs (for muscles tone and power) were done and findings recorded. Other examinations such as sensory level, deep tendon reflexes and bulbocarvanosus reflex were done on spinal diseased patients.

All the patients had their urine samples taken at catheterization for urinalysis and microscopy, culture and sensitivity. Full blood count, serum urea, electrolytes and creatinine (U/E/Cr) and abdominal ultrasound were done on all the patients. Other investigations were individualized depending on the clinical impression of the possible cause of UR and associated complications. These investigations were retrograde urethrogram (RUG), micturating cystourethrogram (MCUG), Abdominal X-ray (KUB), PSA, prostate biopsy, cystoscopy/urethrocystoscopy with or without biopsy. The results of the investigations were retrieved and recorded in the questionnaire during subsequent review in the ward or at urology outpatient clinic for the outpatients.

The generated data was analysed using SPSS version 16.

\section{Results}

The patients seen in this study were adults male of the ages ranged from 17 to 100 years with a mean age of $56 \pm$ 19.3 SD years as shown in Figure 1. Urinary retention was found to be more common in the age range 55 - 74

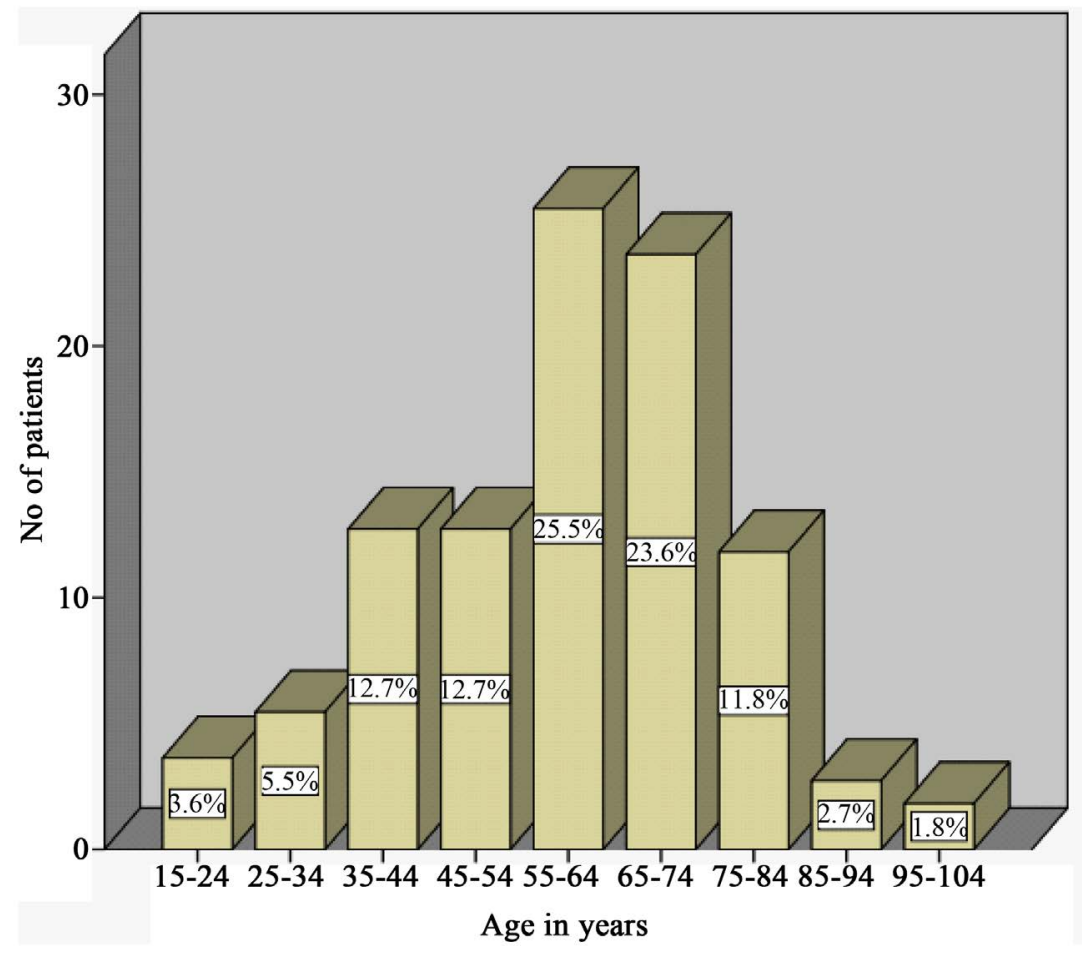

Figure 1. Age distribution among the 110 patients with UR. 
years accounting for almost half of the patients in the study $(25.5 \%+23.6 \%=49.1 \%)$. Patients within the ages of 35 - 44 years and 45 - 54 years accounted for $12.7 \%$ each. The much older age group ( $\geq 85$ years) and the younger ( $\leq 24$ years) had the lowest rate of developing UR.

Following the initial management of the patients, causes of UR found are shown in Table 1 below. BPH was found to be the commonest cause of urine retention accounting for $51.8 \%$ of the causes. This is followed by urethral stricture and prostate cancer accounting for $20 \%$ and $7.3 \%$ respectively (Table 1). Table 2 shows grouping of the patients based on the causes of UR, mean age and standard deviation.

From this study, majority of the patients (53.4\%) were found to have AUR, 30.5\% had CUR while $16.1 \%$ developed acute-on-chronic UR as shown in Figure 2. The causes in each of the type of UR were also analyzed and presented in Table 3. Similarly, patients were evaluated at presentation for complications associated with the UR. Complications are not very common as $60 \%$ of the patients did not have any complication. Urinary tract infection is the most common complication following UR (17.3\%), this is followed by renal impairment and anaemia (Table 4).

Of the 27 (24.5\%) patients who had documented UTI at presentation, E. coli was cultured in 17 (63\%) patients, Klebsiella specie in 6 (22.2\%) patients, and Pseudomonas aeroginosa in the remaining 4 (14.8\%) patients. The patients found to have anaemia (11.8\%) had haemoglobin that ranged from $6 \mathrm{~g} / \mathrm{dl}$ to $8 \mathrm{~g} / \mathrm{dl}$ with a mean of $7.2 \pm 1 \mathrm{SD}$ g/dl. In the patients with renal impairment (14.5\%) various degree of derangement in U/E/Cr was recorded. However, 4 of the patients had haemodialysis based on biochemical indication.

All the complications observed above were seen in the patients with CUR and acute-on-chronic UR.

In $61.0 \%$ of the patients, the retention was successfully relieved by urethral catheterization, while in the remaining $39.0 \%$ the retention was relieved by SPC (Figure 3).

\section{Discussion}

Urinary retention is one of the common urological emergencies in our environment. It is commonly caused by $\mathrm{BPH}$, urethral strictures, prostatic cancer, urethral trauma, bladder tumour and stones.

Urinary retention was found in this study to be commoner among middle aged and the elderly. Those in the age group $60-79$ years constitute the largest group $(27.3 \%+21.8 \%=49.1 \%)$. The patients within the age group of 20 - 29 years accounted for $12.7 \%$. The much older age group ( $\geq 90$ years) and the younger ( $\leq 20$ years)

\begin{tabular}{ccc} 
Table 1. Causes of urinary retention $(\mathrm{n}=110)$. & & \\
\hline Causes of UR & No of patients & Percent \\
\hline BPH & 57 & 51.8 \\
Urethral stricture & 22 & 20.0 \\
Cancer of the prostate & 8 & 7.3 \\
Urethral injury & 8 & 7.3 \\
Bladder tumour & 7 & 6.4 \\
BPH and Urethral stricture & 4 & 3.6 \\
Bladder/Urethral stone & 2 & 1.8 \\
Bladder neck stenosis & 1 & 0.9 \\
Total & 1 & 0.9 \\
Cancer of the prostate and Urethral stricture & 110 & 100
\end{tabular}

Table 2. Age distribution of 110 patients based on their cause of urinary retention.

\begin{tabular}{ccc}
\hline Causes of UR & Mean age (years) & Standard Deviation (SD) \\
\hline BPH & 66.5 & 10.8 \\
Urethral stricture & 40.9 & 13.2 \\
Cancer of the prostate & 68.5 & 6.5 \\
Urethral trauma & 24.6 & 5.0 \\
Bladder tumour & 50.9 & 13.5 \\
\hline
\end{tabular}


Table 3. Causes of different types of urinary retention $(n=110)$.

\begin{tabular}{|c|c|c|c|c|}
\hline \multirow[b]{2}{*}{ Causes of UR } & \multicolumn{3}{|c|}{ Types of UR } & \multirow[b]{2}{*}{$\begin{array}{l}\text { Total } \\
\text { No (\%) }\end{array}$} \\
\hline & $\begin{array}{c}\text { Acute } \\
\text { UR } \\
\text { No (\%) }\end{array}$ & $\begin{array}{c}\text { Chronic } \\
\text { UR } \\
\text { No (\%) }\end{array}$ & $\begin{array}{l}\text { Acute-on-chroni } \\
\text { c UR No (\%) }\end{array}$ & \\
\hline $\mathrm{BPH}$ & $31(52.5)$ & $18(53)$ & $8(47.0)$ & $57(51.8)$ \\
\hline Urethral stricture & $11(18.6)$ & $7(20.6)$ & $4(23.5)$ & $22(20.0)$ \\
\hline Urethral injury & 8 (13.6) & - & - & $8(7.3)$ \\
\hline Cancer of the prostate & $3(5.1)$ & $3(8.8)$ & $2(11.8)$ & $8(7.3)$ \\
\hline Bladder tumour & $4(6.8)$ & $3(8.8)$ & - & $7(6.4)$ \\
\hline $\mathrm{BPH}$ and urethral stricture & - & $2(5.9)$ & $2(11.8)$ & $4(3.6)$ \\
\hline Bladder/urethral stone & $2(3.4)$ & - & - & $2(1.8)$ \\
\hline $\begin{array}{c}\text { Cancer of the prostate and urethral } \\
\text { stricture }\end{array}$ & - & $1(2.9)$ & - & $1(0.9)$ \\
\hline Bladder neck stenosis & - & - & $1(5.9)$ & $1(0.9)$ \\
\hline Total & $59(100)$ & $34(100)$ & $17(100)$ & $110(100)$ \\
\hline
\end{tabular}

Table 4. Complications of urinary retention in 110 patients.

\begin{tabular}{ccc} 
Complications & No of patients & Percent \\
\hline None & 66 & 60 \\
Urinary tract infection & 19 & 17.3 \\
Renal impairment & 7 & 6.4 \\
Anaemia & 6 & 5.5 \\
Renal impairment and UTI & 5 & 4.5 \\
Renal Impairment and anaemia & 4 & 3.6 \\
Anaemia and UTI & 3 & 2.7 \\
Total & 110 & 100 \\
\hline
\end{tabular}

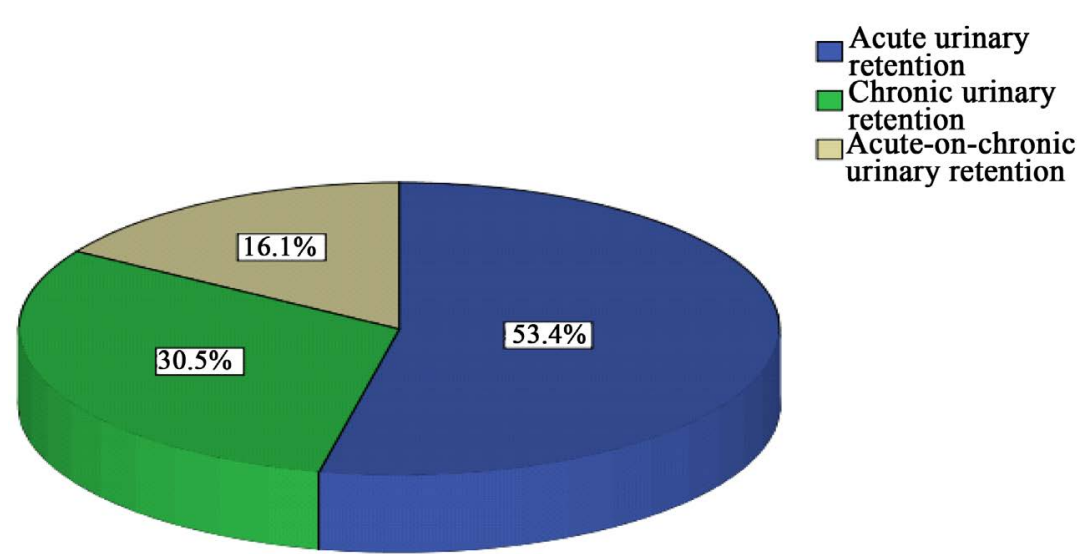

Figure 2. Different types of urinary retention in 110 patients.

had the lowest rate of developing urinary retention of 2.7\% each. The largest age group in this study was similar with the findings by John MF, et al. in "Management of Acute Urinary Retention: a Worldwide Survey of 6074 Men with Benign Prostatic Hyperplasia” [3]. In their study 39.3\% of the patients who presented with AUR were between the ages of 65 - 74 years. Others were 33.3\% those above the age of 75 years and $27.4 \%$ were less than 65 years. The difference in the second most prevalent age group could be because this study was on all causes of UR which have different peak age of presentation. The high prevalence of UR in patients above the age of 60 years is expected as UR is generally known as a disease of the middle aged and the elderly because a significant 


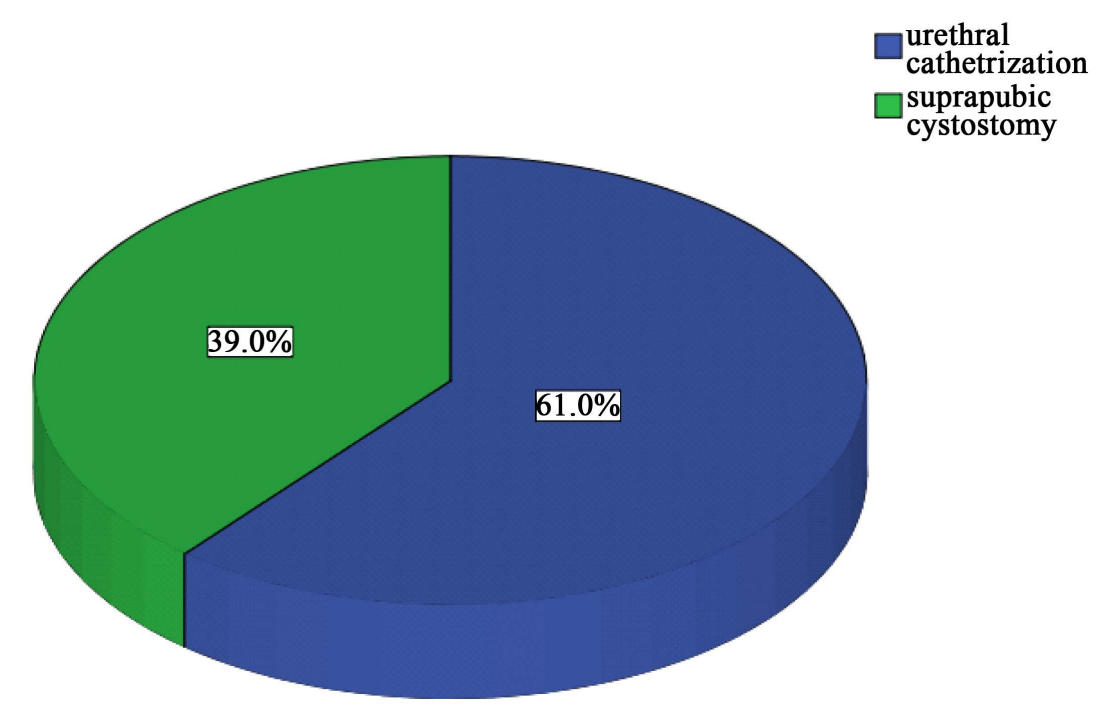

Figure 3. Methods of relieving urinary retention.

percentage of the causes of UR such as BPH and cancer of the prostate are commoner in the said age group.

The mean age of patients who presented with UR from BPH in this study (66.5 \pm 10.8 SD years) was similar to the finding in a previous study on benign prostatic hyperplasia and prostate carcinoma in native Africans done at Zaria, Nigeria, which found a mean age of 66.1 years among 545 patients with BPH 65. Studies from other parts of the world also showed similar findings as reported in "Management of Acute Urinary Retention: A Worldwide Survey of 6074 men with Benign Prostatic Hyperplasia” [3]. In this study mean age of 65 years, 68 years and 70 years respectively were reported for patients from Middle East, Latin America and Asia respectively. However, the mean age of the patients from France was 72 years. The patients who presented with UR from urethral stricture were younger than those with $\mathrm{BPH}$, the mean age being $40.9 \pm 13.2 \mathrm{SD}$ years. This is similar to findings in other studies such as the one by Ahmed A, et al. in Zaria, Nigeria who found the mean age of $40 \pm 12.9$ SD years among 556 male patients with urethral stricture [13]. Similarly, Ahmed GI, et al. in their study on "One-Stage Urethroplasty for Strictures in Maiduguri, North-Eastern Nigeria" found a mean age of $45.6 \pm 19.7$ SD years among 91 patients studied [14]. The finding was consistent with the known age of presentation of both BPH and urethral stricture [1]. The mean age of patients with UR from prostate cancer was higher than that of BPH; this is also expected as cancer of the prostate has been known as the disease of the older age patients [1].

From this study the mean age of patients with UR from Bladder Tumour was 50.9\%; this was also similar to the findings of Ochicha $\mathrm{O}$, et al. in a previous study on bladder cancer in Kano [15] in which they found a mean age of 48.8 years. However, it significantly differs from findings in other parts of the world which put the peak incidence of bladder cancer at the seventh decade in England and Wales while the median age was 65 years in the USA [16]. This is probably because most bladder cancers in Kano were predisposed by previous schistosomiasis [15] which has been shown to present earlier than the one from other risk factors.

The most common cause of UR from this study was BPH in $51.8 \%$ of the patients. This was followed by urethral stricture in $20 \%$, cancer of the prostate and urethral trauma were each responsible for UR in $7.3 \%$ of the cases, and bladder tumour accounted for $6.4 \%$ and bladder /urethral stone in $1.8 \%$. Some patients were found to have more than one cause; 3.6\% of the patients had both BPH and urethral stricture. These were similar to findings in other studies such as the one conducted by Yeboah, et al. at Korle Bu Teaching Hospital, Accra, Ghana from 1982 to 1989 on 1124 patients [1]. They also found BPH to be the most common cause (46.7\%), followed by urethral stricture (31.4\%). Others were prostatic cancer $13.8 \%$, urethral rupture $3.6 \%$, and bladder tumour $0.5 \%$, while both BPH and urethral stricture were found in $1.2 \%$ of cases. The differences in the percentages of patients may be explained by the differences in the sample size and the duration of the study. However, the percentage of the patients with bladder tumour is much higher in this study. This could be explained by the high prevalence of bladder tumours in our environment as shown by Ochicha O, et al. in an earlier study [15].

Similarly, the causes of urinary retention found by Yenlia EMT, et'al. in Kumasi, Ghana were similar to our 
findings except for the low percentage of patients with bladder tumour as noted above.

Bassey Tom Etuknwa in his study on the management of urinary retention in rural areas at Uyo, Akwa Ibom State, Nigeria found BPH to account for up to in 92\% of causes of UR, cancer of the prostate in 6\%, and urethral stricture in 4\% [17]. The high percentage of $\mathrm{BPH}$ and low percentage for urethral stricture may be due to the fact that, included in the study were patients who presented with urethral catheter in-situ. Hence, there were more chances to include patients with UR from BPH.

The causes in different types of UR were also similar to the findings in general causes. In AUR, CUR and acute-on-chronic UR, BPH was the leading cause followed by urethral stricture.

Complications of UR such as UTI, renal impairment, urinary stones, and anaemia are known to be more commonly associated with chronic or acute-on-chronic UR [18]. From this study, 60\% of the patients at presentation had no associated complications. Of the complications recorded among the remaining patients, UTI was the most common (24.5\%), followed by renal impairment (14.5\%) and anaemia (11.8\%). These complications occurred singly or in combinations, and were all seen in patients with chronic or acute-on-chronic UR. The finding is consistent with the established pathophysiology of urinary obstruction where most of these complications are seen in patients with chronic stasis of urine. The findings are also similar to those of El Imam, et al. in their study in Sudan [19]. They found thatacute urinary obstruction was associated with normal renal function while chronic urinary obstruction was associated with renal impairment [19]. They also found that majority of the patients with obstructive uropathy (66.4\%) had chronic obstruction out of which 5.2\% did not recover even after relieving the obstruction.

Similarly, all the organisms responsible for UTI in this study were gram negative bacteria, which are the commonest pathogens of the urinary tract [10] [20]. The findings were similar to the one found by Abaeze S, et al. in a study on "The prevalence of urinary catheter related infections in Federal Medical Centre, Abeokuta, Nigeria” [21] and Christian Kofi Gyasi-Sarpong, et al. at Kumasi, Ghana [22]. In both studies, E. coli was the commonest pathogen isolated, followed by Klebsiella specie. Others were Staphylococcus aureus and Pseudomonas specie. However, Taiwo SS, et al. in Osogbo, Nigeria [23] found Klebsiella specie to be the commonest bacteria cultured followed by E. coli, Staphylococcus aureus and proteus mirabilis. In all the studies, the organisms cultured were predominantly gram negative enterobacteriacae which conforms to the earlier reports on pathogenic organisms affecting the urinary tract [10] [20].

\section{Conclusion}

Urinary retention is common among the middle aged and the elderly men; the age of presentation may suggest the likely cause of the retention. BPH was the leading cause of UR in our environment, but urethral stricture, prostatic cancer and bladder tumour still remain important causes. Though AUR is the commonest form of UR, CUR and acute-on-chronic UR were associated with complications such as renal impairment and UTI. Most UR could be relieved by urethral catheterization, and SPC was only offered in failed urethral catheterization or where it was contraindicated.

\section{References}

[1] (2010) Urethra, Penis and Prostate. In: Klufio, G.D., Yeboah, E.D., Badoe, E.A., Archampong, E.Q. and da Rocha Afodu, J.T., Eds., Principles and Practice of Surgery including Pathology in the Tropics, 4th Edition, Ghana Publishing Company, Accra, 881-883, 914-915, 920-952.

[2] Odunayo, K. and Mark, J.S. (2009) Management of Acute and Chronic Retention in Men. European Urology Supplements, 8, 523-529. http://dx.doi.org/10.1016/j.eursup.2009.02.002

[3] John, M.F., Francois, D., Kamel, A., et al. (2011) Management of Acute Urinary Retention: A Worldwide Survey of 6074 Men with Benign Prostatic Hyperplasia. BJU International, 109, 88-95.

[4] Brian, A., Selius, D.O. and Rajesh, S. (2008) Urinary Retention in Adults: Diagnosis and Initial Management. American Family Physician, 77, 643-650.

[5] Mbibu, N.H., Nwofor, A.M.E. and Khalid, L. (2002) Spectrum of Urologic Disease in the West African Sub Region. Annals of African Medicine, 1, 44-52.

[6] Fall, B., Diao, B., Fall, P.A., et al. (2008) Urological Emergencies at the Dakar University Teaching Hospital: Epidemiological, Clinical and Therapeutic Features. Journal de L'Association Francaise D'urologie et de la Societe Francaise D’urologie, 18, 650-653. http://dx.doi.org/10.1016/j.purol.2008.04.004 
[7] Patterson, J.M. and Chapple, C.R. (2007) Failure of Urinary Drainage: Lower Tract. In: Markus, H. and Santucci, R.A., Eds., Emergencies in Urology, 118-131. http://dx.doi.org/10.1007/978-3-540-48605-3_11

[8] Ndaguatha, P.L.W. (2003) Unusual Bladder Outflow Obstruction by Hydatid Disease: Case Report. East African Medical Journal, 80, 388-390.

[9] Policastro, M.A. (2011) Urinary Obstruction. http://emedicine.medscape.com/article/778456-overview

[10] Wagenlehner, F.M.E., Pilatz, A., Naber, K.G., et al. (2008) Therapeutic Challenges of Urosepsis. European Journal of Clinical Investigation, 38, 45-49. http://dx.doi.org/10.1111/j.1365-2362.2008.02008.x

[11] Tanagho, E.A. (2008) Urinary Obstruction and Stasis. In: Tanagho, E.A. and McAninch, J.W., Eds., Smith’s General Urology, 17th Edition, 166-177.

[12] Carlo, L.A., Negro and Gordon, H.M. (2012) Chronic Urinary Retention in Men: How We Define It, and How It Does Affect Treatment Outcome. BJU International, 2, 1-5.

[13] Ahmed, A. and Kalayi, G.D. (1998) Urethral Stricture at Ahmadu Bello University Teaching Hospital, Zaria. East African Medical Journal, 75, 582-585.

[14] Ahmed, G.I., Nuhu, A., Suleiman, A., et al. (2012) One-Stage Urethroplasty for Strictures in Maiduguri, North Eastern Nigeria. ISRN Urology, 4, 847-870.

[15] Ochicha, O., Alhassan, S.U., Muhammed, A.Z., et al. (2003) Bladder Cancer in Kano-A Histopathological Review. WAJM, 22, 202-204.

[16] HMSO (1993) Registration of Cancers Diagnosed in 1987, England and Wales. Office of Population Census and Surveys, London.

[17] Etuknwa, B.T. (2006) Management of Urinary Retention in Rural Areas. Nigerian Journal of Surgical Sciences, 16, 31-34. http://dx.doi.org/10.4314/njssci.v16i1.38371

[18] Herbert, L. (2004) Pathophysiology, Epidemiology, and Natural History of Benign Prostatic Hyperplasia. Reviews in Urology, 6, 3-10.

[19] El Imam, M., Omran, M., Nugud, F., et al. (2006) Obstructive Uropathy among Sudanese Patients. Saudi Journal of Kidney Diseases and Transplantation, 17, 415-419.

[20] John, L.B., Michael, S.B. and Francisco, T. Catheter-Related Urinary Tract Infection. http://emedicine.medscape.com/article/2040035-overview.2013

[21] Abaeze, S. and Abasiama, J.S. (2011) The Prevalence of Urinary Catheter Related Infections in Federal Medical Centre, Abeokuta, Nigeria. International Journal of Pharmaceutical and Biomedical Sciences, 2, 81-85.

[22] Gyasi-Sarpong, C.K., Mwintiereh, E., Taang, Y., et al. (2012) Bacterial Urinary Tract Infections among Males with Lower Urinary Tract Obstruction at Komfo Anokye Teaching Hospital, Kumasi, Ghana. Open Journal of Urology, 2, 131-136. http://dx.doi.org/10.4236/oju.2012.23023

[23] Taiwo, S.S. and Aderounmu, A.O.A. (2006) Catheter Associated Urinary Tract Infection: Aetiologic Agents and Antimicrobial Susceptibility Pattern in Ladoke Akintola University Teaching Hospital, Osogbo, Nigeria. African Journal of Biomedical Research, 9, 141-148.

\section{Submit or recommend next manuscript to SCIRP and we will provide best service for you:}

Accepting pre-submission inquiries through Email, Facebook, Linkedin, Twitter, etc

A wide selection of journals (inclusive of 9 subjects, more than 200 journals)

Providing a 24-hour high-quality service

User-friendly online submission system

Fair and swift peer-review system

Efficient typesetting and proofreading procedure

Display of the result of downloads and visits, as well as the number of cited articles

Maximum dissemination of your research work

Submit your manuscript at: http://papersubmission.scirp.org/ 